\title{
Etymologia upanishadica
}

\section{辻值四郎}

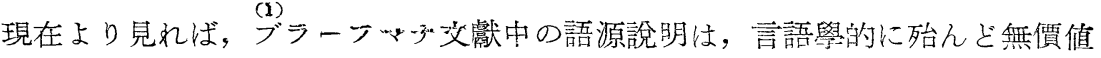
と云つてよい。その外形のみを捉えれば，最子奔放な通俗語源（Volksetymologie）と比較しても遜色がない。然しこれはウパニシャッドを含む古代梵語散文 の一特徴であり古代の瞑想家にとつては，これにょり事物の真相に值參せんをす る真劒な說明法であり, 彼等の呚義の一部であつた。印度に發達した高度の文法 的分析の先駱として, 或は黄の語源學・文典學と並行して提唱されたこの種の語 源說明を組織的に蒐集することも, 梵語文䙐學の一課題と考える。以下所謂古代 散文ウパニシャッド，郎ちブリハッドアーラニヤカ(BAU), チャーンドーギヤ

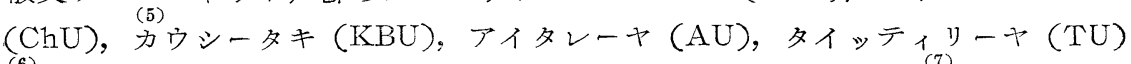
ケーナ $(\mathrm{KeU})$, プラシュナ $(\mathrm{PU})$, マーンドゥーキャ( の中に散在する語源說明を一括して表示する。茲には語源說明を廣義に解し，音 形類似の語による解說, 或は少くも二語の間に何等かの語源的關聯を意識して書 いたと思われる場合をも，全て含めることとした。但し上記の範圍以外に瓦り， 廣く新古交獻からの類例は附記しない。時に他書より例登を舉げたのは，當該項 目說明の営に，有益と考へた場合にかぎる。

各項目の配列は梵語字母の順序に從い，先ず簡單に畋著者の意に從う語源的分

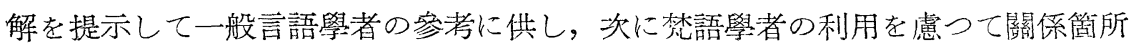
の原文を摘出した。その際屢 ! 原文のサンディを切り離したのは, 原著者の意圖 を一目瞭然たらしめんが爲である。

（註 1）プラーフマナ文獻中の語源說明の眞意に關しては屢了議諭されている。 e. g. Roth: Jāska's Nirukta (1852), p. 221, Th. Aufrecht: Das Aitareya Brāhmaṇa (1879), p. 432 (ad I. 2. 3), S. Lévi: La doctrine du sacrifice (1898), p. 38, n. 6, Winternitz: Geschichte der indischen Litteratur I, p. 177 : Engl. tr. p. 203, Liebich: Zur Einführung in die indische einheimische Sprachwissenschaft II (1919), pp. 6-7, H. Oerte1: Zum altindischen Ausdrucksversiarkungstypus satyasya satyam, SBayAW philos.-hist. Abt. Jahrg. 1937 Heit 3, p. 15, n. 2, 拙諭 「古代印度に於ける語源的說明法に就いて」佛教學の諸問題 (昭和 10 年), 473-479 真. 
(註 2) cf. Oerte1: The Jaiminīya or Talavakāra Upanisad Brāhmaṇa, JAOS XVI (1894), p. 258 (Index II: JUB), Liebich op. cit., pp. 7-8 (: Aitareya-br. I -VI), Deussen Sechzig Upanishad's ${ }^{3}$ (1921), pp. 896-897 (Index sub v. Etymologieen). 侉ニルクタ中の語源的分解は, Sköld: The Nirt1kta (1926), pp. 182364 飞網羅されているから，以下の各項との異同はこれより容易に知ることが出來る。

（註 3）古代韻交ウパニシャッドに關しては，カータカ(KU) から一例 (下記 No. 47) を擧げ得るのみである。

（註 4) 引用は普通に行われるカーンヴァ派所傳に從い，Mはマーディヤンディナ派 所傳を指す。

（註 5) $\mathrm{B}=\mathrm{ed}$. Cowe11, Bib1. ind. (1861); $\mathrm{A}=\mathrm{ed.} \mathrm{AnSS} \mathrm{xxix.}$

（註 6）=JUB Iv. 18-21. 後牛は散交を以て緅られているから，てれをる含めた。

（註 7） ed. Cowe11, Bib1. ind. 2nd ed., 1913-1935を基礎とし，必要に應じ 108 UP. 本 (NSP 3rd ed. 1925) ょり 1ec. var. を添えた。

(註 8) cf. Sköld op. cit., p. 175.

（註 9）少數の例外 (cf. Nos. 3, 10,13,47, 51, 58.1, 60, 70, 72, 74, 76, 80, 86.1, 91, 95.2) を除き，大部分は正鵠を逸した語源である。假令正しい語根を念頭に置いていたと思 われる場合にも，或はその意義相應せず (cf. Nos. 48.2, 55.1,3), 或はその說明法が 適切でない (cf. Nos. 33.2, 3, 43, 57.3, 63.2, 64, 65, 77)。

1. a-kāra- ‘ア音': āpti- ‘獲得' 又は ādi- ‘最初', MāU 9: jāgaritasthāno vaiśvānaro 'kāraḥ, prathamā mātrā, aāpter āđimattvād vā, đāpnoti ha vai sarvān kāmān āđiśs ca bhavati ya evain veda.

"2. Angiras- nom. pr. (神話): anga- '肢' +rasa- '精髓', ChU I. 2.

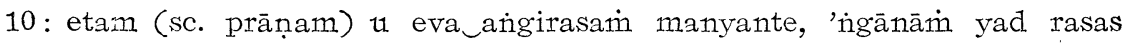
tena.

3. atrnāda- '犢': a- (否定辭) +tṛna- '草' + ada- '食う (ad-)', 郎ち “未だ草を食わざるもの’, BAU I. 5. 2=M I. 5. 5： atha vatsam jātam āhur atṛnāia iti.

4. Atri- nom. pr.=*Atti : atti 3. sg. praes. ad-'食5', BAU II. 2. 4= M II. 2. 6: vāg eva_atrir, vācā hy annam adyate; 'ttir ha vai nāmaitad yad atrir iti.

5. Aditi- '女神名' : atti 3. sg. praes. ad- '食5', BAU I. 2. 5=M I. 2. 5: sa (sc. mrtyıh ) yad yad evāsrjata, tat tat attuim adhriyata; sarvam vā attiti tad aditer adititvam.

6. adhi-śí- '上に橫わる, to lie down upon', adhi: adhas “下に', BAU 
III. 1. 8=M III. 1. 10 : yā (sc. āhutayah) hutā adhiśerate, mantisyalokam (M pitṛlokam) eva tābhir jayaty, adha iva hi mantısyalokah (M pitṛlo$\mathrm{kah})$.

7. adhyardha- '一牛' =風神 Vāyu: adhyārdhnot 3. sg. imperf. adhyrdh- “繁榮す', BAU III. 9. 9=M III. 9.10: tad āhur : yad ayam eka ivaiva (M om. iva) pavate, 'tha katham adhyardha iti; yad asminn idam sarvam adhyärdhnot, tena_adhyardha iti.

8. ana- “氣息, prāṇa ':anna- “食物’ 及び anagna- “裸體ならざる’, BAU vi. 1. $14-15=\mathrm{M}$ vi. 2.14-15: tasya (sc. prāṇasya) me kim annam kimi vāsa iti; yaḍ iđam kim cā śvabhya(ḥ) …...tat te 'nnam, āpo vāsa iti; na ha vā asya_anannam jagđham bhavati; ya evam etad anasya_annam veda. tad viđvāinsah śrotriyā aśiṣyânta ācāmanty aśitvācāmanty, etam eva tađ anagnam kitvanto manyante, ( $M$ contin. : .....etam eva tad anam anagnam kurute.). simil. ChU v. 2. 1-2.

9. anāśakāyana- “斷食': *a-nāśaka-ayana- ‘不滅への到達': na naśyati “滅亡せず', ChU viIr. 5. 3: atha yad anāśakāyanam ity ācakṣate, brahmacaryam eva tad, eșa hy ātmā na naśyati, yami brahmacaryeṇānuvindate.

10. anna- “食物': ad- “食官', TU II. 1: adyate 'tti ca bhūtāni, taśmād annam tad ucyate. cit. MU vi. 12 fin.

11. ap-, āpah p1. ‘水', 门)：apa-ji- “克服す', BAU III. 2. 10=M III. 2. 10: agnir vai mrtytuh, so 'pām annam, apa punarmrtyum jayati [ya evaim veca, cf. Hume p. 110, n. 1]. 2): āpyāyana-<ā-pyai '膨脹す', MU vi. 7 : p. 67.1 : āpo "pyāyanāt.

12. apad- “足なき’(“落つることなき’の義を争ぬ)：pad- “落つ’, BAU v. 14. $7=\mathrm{M}$ v. 15. 10. : apad asi, na hi padyase.

apatを nom. sg. fem. に用い, apāt 又は apadī (cf. Wackernagel Altind. Gr. III. § 129 : pp. 235-236) としないのは, 上記の二義を争外しめんが爲である。 13. apāna- '入息' : apa-an- '入息す', ChU I. 3. 2: yad apāniti so 'pānaḥ.

14. ama- pron. indef. (?): amā '家に於て, domi', ChU v. 2. 6: amo näināsy amā hi te sarvạn iđam. "Du heissest Ama und Alles hier ist bei (amā) dir." (Böhtlingk)

この䈯所に於ける ama の黄義は明瞭でない (cf. Wackernage1 Altind. Gr. III, p. $533: \S 251$. h, Anm., p. $494: \S 242$ c Anm.). contra Deussen (" der 
Gewaltige ”) v. Böhtlingk BSGW xLIx. (1897)，pp. 88 fin.—89. これに相當 する BAU vi. 3. 5 : āmaninsy āmaninhi te mahi, M vi. 3. 10: āmo 'sy āmam hi te mayi の意義は更に不明瞭である。

15. Ayāsya- nom. pr. 1): ayam '彼'十āsya- ' 口', BAU I. 3. $8=\mathrm{M}$ I. 3. 9: ayam (sc. prāṇaḥ) āsye 'ntar iti so 'yāsyaḥ. cf. Āningirasa-.

從つて本來 *Ayamāsya- とあるべきである, cf. JUB II. 8. 7 : …… tasmād ayamāsyaḥ. ayamāsyo ha vai nāmaị̣ah. tam āyāsya iti parokṣam ācaksate, (cf. II. 11. 8-9).

2): ayate 3. sg. praes. ay $=\mathrm{i}$ '行く'十āsya- ' $\square$ ' ChU I. 2. 12: tain (sc. prāṇam) u eva_ayāsyatin manyanta, āsyād yad ayate tena.

16. araṇyāyana- ‘森林に隱遁すること’, araṇya- ‘森林”: *ara-+*ṇya“梵界に於ける二つの海の名’, ChU viII. 5. 3: athá yad araṇyāyanam ity ācakṣate, brahmacaryam eva tad; araś ca ha vai ṇyaś cārṇavau brahmaloke tṛtīyasyām ito divi ; .....4: tad ya evaitāv aramin ca ṇyañ cārṇavau brahmaloke brahmacaryeñānuvindanti, .....

17. arka- '火’: arc- '讚む'+kam “喜悅, stukha (cf. Nir. III. 6),' BAU I. 2. $1=\mathrm{M}$ I. 2. 1: so (sc. mrityự) 'rcann acarat; tasya $a$ rcata āpo 'jāyanta, arcate vai me kam abhūd iti ; tad eva_arkasya_arkatvam (M mss., Weber: arkyasya_arkatvain, cf. Böhtlingk ed. p. 69 ad loc., Eggeling SBE xLIII, p. 402 cum n. 1, Oerte1 JUB p. 245 ad Iv. 23. 4).

この語源は arkka-なる發音を豫定している，cf. Wackernage1 A1tind. Gr. I, p. $113: \S 98$ a Anm.

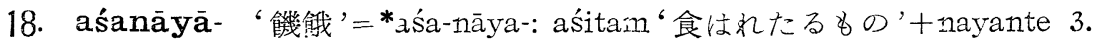
p1. praes. nī “導く', Ch̉U vi. 8. 3 : yatraitat puruṣo 'śiśisati nāma,āpa eva tad aśitamin nayante. cf. udanyā-.

19. aśvamedha- “馬祠' : aśva- “馬’ (:aśvat 3. sg. aor. śvi-“膨脹す’) +medhya- “供膆に適する’, BAU. I. 2. 7=M I. 2.7: tato 'śvah sa:mabhavad, yad: aśvat, tan (sc. śarīram) medhyam abhūd iti, tad eva_aśvamedhasya aśvamedhatvam.

yad aśvat を前行文に屬せしもべきか（Śankara，M. Mü1ler，Deussen，Hume)，或は後續文に屬せしむべきか (Böhtlingk, Eggeling SBE xLIII, p. 403 cum n. 3, Senart), 問題とされているが, aśva-の語源を念頭に置いたことは疑 なく，恐らく前後兩文に屬する一種の 'Satzhaplologie' と解すべきであろう。

20. asāman- ‘サーマンならざるもの’, : asādht1-, v. sub sāman- 4): 
sādhı.

21. ahan- '日': han- “擊滅す”, 及び hā- “裹却す', BAU v. 5. 3=M v. 6. 4: tasya (i. e. ya eșa etasmin maṇdale puruṣah) upaniṣad ahar iti; hanti pāpmānain jahātí ca, ya evain ređa. cf. aham

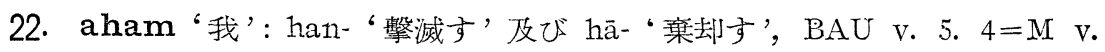
6. 5: tasya (i. e. yo 'yam daksiṇe 'Kșan puruṣah) upaniṣad aham iti; hanti pāpmänain jahäti ca, ya evain veda. cf. ahan-

23. Ángirasa- nom. pr.: anga- “肢'+rasa- '精髓' (cf. Angiras-), BAU

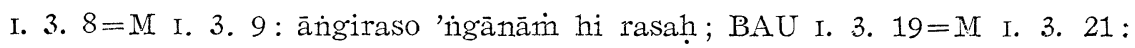
so 'yāsya āngiraso 'ñgānām hi rasạ̣ cf. Ayāsya-.

24. ādi- ‘サーマンの七部分の第三', 1): ā praev., ChU II. 8. 1: yad ā iti sa āđị.

2): $\bar{a}-$ dā- '取る' (āđāyātmānam ‘sich haltend'), ChU II. 9.4 : tasmāt tāny (sc. vayāminsi) antarikṣe 'nārambaṇāny āđāyātmānaim paripatanty; āđibhājino hy etasya sāmnah.

25. Äditya- P1. ‘神群の名’, 1): ā-đā- ‘取る', ChU III. 16. 5 : prāṇā vāva`ādityā; ete hīdam sarvam ādadate.

2) : ādadānā yanti ‘取りつ〉行く', BAU III. 9.5=M III. 9. 6: ete hīdam sarvam ādađānā yanti ; te (M tad) yad idam sarvam ādađānā yanti, tasmāà āđityā iti.

3) ādāna- ‘取ること,' MU vi 7 : p. 96.1: ādānād ādityaḥ.

この語源は奇矯ではあるが廣く行われていた。cf. Muir OST IV, pp. 116一 117, Gertel JAOS xv. p. 240 (: JB Ir. 77), JUB p. 243 (ad Iv. 2. 9).

26. Indra- “神名', 1)=Indha-: indh- “點火す', BAU IV. 2. $2=\mathrm{M}$ IV. 2. 2 ; indho ha (om. M) vai nāmaișa yo 'yam dakṣiṇe 'kṣan puruṣaḥ; tam vā etam indham santam indra ity ācakṣate parokṣeṇaiva ( $M$-ṇeva).

2)=*idaindra- : idam adarśam ‘我これを見たり’，AU I. 3. 14：tasmād

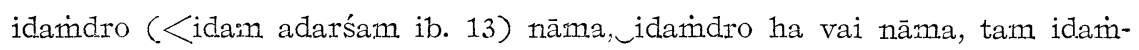
dram santam indra ity ācakșate parokṣeṇa.

この有名な神名に關し如何に多數の語源が考えら期たかは Nir. x, 8 (cf. Skö1d j. 210)より窥われる。茲に擧げた二種の語源もその內に含まれ，2）は特にアウ パマニヤヴァに歸せられている (idam darśanād ity Aupamanyavaḥ). 佔 1) は SB VI. 1. 1.2 にも見えている。

27. ișta- part. praet. pass. yaj- “祭祀す' iș- “希求す', : ChU viIr. 5. 1' 
atha yad iștam ity ācakșate. brahmacaryam eva tad; brahmacaryeṇa hy eva`ișțā`ātmānam antuvindate.

28. u-kāra- “ウ音': utkarșa- <ut-kṛș- ‘高揚す’, 叉は ubhayatva- ‘中間’, MāU 10': svapnasthānas taijasa ukāro dvitīyā mātrāa, utkarșād ubhayatvād vā.`utkarșati ha vai jñānasamtatim, samānaś ca bhavati.

29. uktha- “讃誦'： utt-thā-（=sthā-）“立ち上る，生ず， cat1s. “立たしむ’, BAU I. 6. 1=M I. 6. 1: trayain vā idam: nāma rūpam karma; teṣān nāmnām vāg ity etad eșām uktham, ato hi sarvāṇi nāmāny uttiṣthanti. simil. 2 et 3 ; BAU v. 13. $1=\mathrm{M}$ v. 14. 1: prạṇo vā uktham; prăṇo hìdam sarvam utthāpayaty; ud đhāsmād ukthād viras tisthatị; KBU III. 3 : athı. khalı prāṇa eva prajñātmedam śarīramin parigṛhya_utthāpayati, tasmād etad eva_u1ktham upāsīteti (bis B; A om. iti).

この語源は uktha-を Prākrit に於ける゙如く (cf. Pischel Pkt-Gr., p. 187: $\S 270$ No. 2), uttha- と發音することを豫定している。

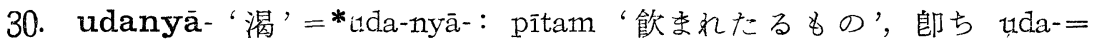
udan-, udaka- '水'+nayante 3. p1. praes. ni- '導人', ChU vi. 8. 5 : atha yatraitat puruṣo pipāsati nāma, teja eva tat pịtam nayante. cf. aśanāyā-.

31. udāna- '五氣の一'<ud-an- '上方人息す' : ūrdhva- '上方の'+nayati 3. sg. praes. nī- '導く', PU III. 7: athaikayā (viz. susumnayā) udānah punyena punyatio lokam nayati.

恐らく語源的說明は意圖されていないと思うが，他の事例を考慮してここに加 えた。 (f. prāṇa- 2), samāna-.

32. udgātṛ- “歌咏祭官”, v. sub udgītha- 2) (ChU I. 6. 8).

33. udgitha- ‘歌咏, サーマンの主要部分’ 1): ud praev.+gir-“聲”+sthitapart. praet. sthā '立つ', ChU I. 3. 6: atha khalu_udgîthākṣarāṇy upāsīta, ud-gī-tha iti ; prāṇa eva`ut, prāṇena hy ưttiṣṭhati ; vāg gīr, vāco ha (Böht1. hi) gira ity àcakșate ; 'nnam tham, anne hîdam sarvam sthitam. (cf. ib. 7 ; M. Mü1ler SBE I, p. 8, n. 1).

2): ud+geșna- '歌' (<gai- '歌子', =parvan- “關節' Śankara), ChU I. 6. 7 : tasya (i. e. ya esa 'ntarāditye......pururusaḥ) ưd iti nāma, sa eșa sarvebhyaḥ pāpmabhya udita; udeti ha vai sarvebhyah pāpmabhyo, ya evam veda; 8: tasyark ca sāma ca geṣnau; tasmād udgīthas; tasmāt tv eva ưdgātā, etasya h̆i gāāā.

3): uccaị “高らかに’ (cf. u1 praev.) + gāyanti 3. p1. praes. gai- “謳歌 
す’, ChU 1. 11. 7 : sarvāṇi ha vā imāni bhūtāny ādityam uccaị̣ santaì gāyanti, saiṣā devatā`ı̇dgìtham anvāyattā.

4) 'サーマンの七部分の第四': ud praev., ChU II. 8. 2: yad ud iti sa tudgīthah. cf. ādi- 1).

34. upadrava- “サーマンの七部分の第六’ 1)：upa praev., ChU II. 8. 2: yad rupa_iti sa upadravah. cf. ādi- 1).

2) upa-dru- '走り近づく', ChU II. 9. 7: tasmāt te (sc. āraṇyāḥ) purușam đ̛̣ștvā kakṣam śvabhram ity upadravanty, upadravabhājino hy etasya sāmmaḥ. cf. ädi- 2).

35. ' rc- '詩節, 頌' abhy-arc- '讃屯', KBU II. 6 (B) =II. 4 (A) : tad (sc. uktham) ṛg ity upāsìta, sarvāṇi hāsmai bhūtāni śraiṣthyāya_abhyarcyante (B, caus. pass. ? ; abhyarcante A, med.!).

36. kam '嘉怊' =kham '虛宾, ākāça' ChU IV. 10. 5 : te (sc. agnayah) hocur: yad vāva kam tad eva kham, yad eva kham tad eva kam iti.

37. kșatra- '主權': Kșan- “害す'+trai- “救ふ心', BAU v. 13. 4=M v. 14. 4: prāṇo hi vai kṣatrain, trāyate hainam prāṇaḥ kṣaṇitoh; pra kṣatram atram ( $M$ kșatramātram) āpnoti.....ya evamin veda.

他に用例のない atra-を用いたのは一種の Wortspie1 と思はれる, na trāyate 'nyena kenacid ity atram ete. ('Śñkara), 'furchtlos' (Deussen), cf. Senart p. 98 n. 1. 但し M は kṣatramāitram 'Inbegriff des Kriegerstandes' (Böht1.) と詯み，注釋者 Dvivedaganga は kṣatram ātram と解することを許してい る。これに從えば ātra-は“完全に保護する’義であると云う：ā sāmastyena trāyate pālayatîty ātram (ed. Weber: ātrastam, cf. M. Müller SBE xv. p. 195, ก. 3).

38. kha- '虚空', v. sub kam (ChU IV. 10. 5).

39. gāyatrī- “韻律の名, 特に Sāvitrī 頌'，1): gaya- '家族' +trai- '保護 f', BAU v. 14. 4=M v. 15. 7 : sā haị̄ā (sc. g̣āyatrī) gayāịns tatre; prāṇā vai gayās; tat prāṇāms tatre; tasmād gāyaitrī nāma.

2): gāyati 3. sg. praes. gai- '謳歌す' +trai- “保護す' ChU III. 12. 1: vāg vai gāyatrī; vāg vā iđami sarvain bhūtami gāyati ca trāyati ca.

40. chandas- “韻律' : chad- ‘身を蔽う', ChU I. 4. 2 : te (sc. devāh) chandobhir acchāđayan; yad ebhir acchādayan, tac chandasāin chandastvam.

41. tadvanam “神祕的隱語の一, "Nach-ihm das-Sehnen” (Deussen, cf. 
Sechzig Upanishad's, p. 109, n. 1)' : (tad- pron. dem. '乙れ’ + ) abhi ...... samināñchanti 3. p1. praes. abhi- sami-väñch- '熱望す', KeU IV. 6 (: 31): tad dha tadvanam nāma. tadvanam ity upāsitavyam. sa ya etad evain veda, abhi hainami sarvāṇi bhūtāni samiaãñchanti.

42. dam- “制御す’, dama- “制御”： da なる音節, BAU v. 2. 1=M v. 2 . 2: tebhyo (sc. devebhyah) haitad akșaram uvāca (i. e. prajāpatih): da iti; vyajñāsiștāa 3 iti; vyajñāsiṣmeti hocur, đāmyateti na āttheti. $3=$ M 4 : tad etad evaiṣā daivī vāg anuvadati stanayitur : da-da-đa iti, dāmyata datta dayadhvam iti ; tad etat trayam śikșed: damam danam dayām iti. cf day-, dà-.

43. darśata- “美觀を呈する': dadríe “顯現せり'3. sg. perf. driś- “見る', BAU v. $14.3=\mathrm{M}$ v. 15. 4 : darśatam padam (i. e. gāyatryaī turīyam) iti, dadrśa iva hy eșah (i. e. ya eṣa tapati)

44. day- '憐む', dayā- '憐壂'! da なる音節, BAU v. 2. $3=\mathrm{M}$ v. 2.4： tebhyo (sc. asrebhyaḥ) haitad akṣaram uvāca: da iťi; vyajñāsișțā 3 iti; vyajñāsiṣmeti hocur, dayadhvam iti na āttheti. dayā- に關しては, dam-, dama-の項下を見よ。

45. dā- ‘與ふ’, dāna- “布施”; da なる音節, BAU v. 2. $2=\mathrm{M}$ v 2. 3 : tebhyo (sc. manușyebhyah) haitad alș̣aram uvāca: da iti; vyajñāsișțā 3 iti ; vyajñasiṣmeti hocur, datteti na àttheti. đāna- に關しては, dam-, dāmaの項下を見よ。

46. dūr-“神格としての生氣 (Prāṇa) の名”： dūra- ‘遠き’, BAU I. 3.9= M I. 3. 10 : sā vā eṣā devatā dūr nāma, dūram hy asyā mṛtyuh.

47. nāciketa- ‘ナチケータスに屬する': Naciketas- nom. pr., KU I. 19 : eșa te (sc. naciketaso) 'gnir nāciketaḥ svargyo, yam avṛ̣ịthā dvitīyena vareṇa. cf. ib. I. 16: tavaiva nāmnā bhavitāyam agnị̣, I. 18 (nāciketa-, triṇāciketa-).

48. nidhana- ‘サーマンの七部分の最後', 1): ni praev., ChU II. 8. 2: yan ni_iti tan nidhanam. cf. àdi- 1).

2): ni-chā- '埋葬す', ChU II. 9. 8: atha yat prathamāstamite tan nidhanam; tad asya (sc. ādityasya) pitaro 'nvāyattās; tasmāt tān nidadhati, nidhanabhājino hy etasya sāmnaḥ. cf. āđi- 2).

49. pati- '夫', patnī- ‘妻' : pat- caus. ‘落ちし屯’BAU I. 4. 3=M I. 4. 5: sa (sc. ātmā) inam evātmānam dvedhā`apātayat, tatạ̣ patiś ca patnī 
cābhavatām.

50. parorajas- ‘空界の彼方にある, (太陽の形容)’ upari ‘上方に’十rajas“空界', BAU v. 14. $3=\mathrm{M}$ v. 15. 4 : parorajā_iti, sarvam ut hy evaiṣa (sc. ādityah, M om. eva) raja upary-upari tapati.

51. pāvana- '火’: pāvana-<pī- ‘淨む’, MU vi. 7: p. 96. 1: pavanāt pāvanạ. cf M. Mü1ler SBE xv, p. 310, 1n. 3 : pavamānāt pavamānah.

52. putra- '息子' : ( $x+$ trai- “救示'), BAU I. 5. 17=M I. 5. 26: sa yady anena (sc. pitrā) kimcid akṣnayā kṛtam (Röer, Böht1.; akṣnayākṛtam i. e. -yā ak- Śankara) bhavati, tasmāe enain (sc. pitaram) sarvasmāt putro muñcati; tasmāt putro nāma.

一見語源的說明を含ま妨如くであるが，原著者は先づ trāyate ‘救ふ”を念 頭に置き，その synon.として muñcati を使用したものと解される。然し前牛 puーの說明として如何なる語を考えていたかは明瞭でない。恐らく Nir. II. 11 (: pun narakam, tatas trāyata iti vā, cf. Skölca, p. 282) 以來有名な putraの語源たる put- “地獄の名”を念頭に置いていたものと推定する (e. g. MantSn Ix. 138, Vị̣nuSm xv. 44, 郎ち put-tra, cf. Wackernage1 A1tind. Gr. I. p. 113: §98. a, Anm.)。但し Śanjkara は pūraṇa- ‘成滿” なる語を以て說明し ている: tasmāt pūraṇena trāyate sa pitarain yasmāt tasmāt putro nāma; idam tat putrasya putratvam yat pituśs chidram pūrayitvā trāyate, ed. AnSS xv, p. 235. 7-8, simil. Dvivedag. ad ŚB xIv. 4. 3. 26 apud Weber p. 1122. $14-15$.

53. puruṣa- ‘プル゙シャ, 靈體', 1) : pūrva- “前'+tus- ‘燒く', BAU I. 4. $1=\mathrm{M} \mathrm{I} .4,2$ : sa (sc. àtmā) yât pūrvo 'smāt sarvasmāt sarvān pāpmana aușat, tasmāt, purușah.

2)：puri 1oc. ‘都城に, 郎ち身體に’+śaya- “橫る’, BAU II. 5. 18=M II. 5 . 18: sa vā ayain puruṣạ̣ sarvāsu pūrṣı puriśayaḥ. cf. PU v. 5: param puriśayam purusam î̉ṣate. 拙諭, 言語研究第一號 (昭和十四年), p. $44 \mathrm{cum}$ 11. 9 參照。

54. Pūṣan- “神名' : puṣ- “養う', BAU I. 4. $13=\mathrm{M}$ I. 4. 25 : iyam (sc.

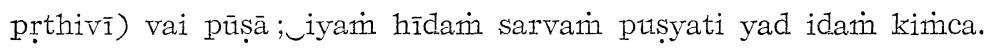

55. pratihāra-1) ‘ーーマンの第四部分': pratiharamāṇa- part. praes. med. prati-hṛ-‘懾取す’, ChU I. 11. 9: annam iti hovāca, sarvāṇi ha vā imāni bhūtāny annam eva pratiharamāṇāni jīvanti, saiṣā devatā pratihāram anvāyattā. cf. udgeìtha- 3). 
2) 'サーマンの七部分の第五' : prati praev. ChU II. 8. 2: yat prati_iti sa pratihāraḥ. cf. ādi- 1).

3) 同上: prátihṛta- part. praet. pass. prati-hṛ- “保持す’ ChU II. 9. 6: atha yad ürdhvam madhyaminināt prāg aparāhṇāt sa pratihāras; tad asya (sc. āđityasya) garbhā anvāyattās; tasmāt te pratihṛ̂ā nāvapađyante ; pratihārabhājino hy etasya sāmnaḥ. cf ādi- 2).

56. pratyāsvara- v. sub svara- (ChU I 3. 2).

57. prastāva- 1) 'サーマンの第二部分'： prāṇa- '生氣 (prastāva の神格と して)', ChU I. 11. 5 : prāṇa iti hovāca, sarvāṇi ha vā imāni bhūtāni prāṇamn evābhisaminiśanti ; prāṇam abhyujjihate, saiṣā devatā prastāvam anvāyattā. cf. udgīitha- 3).

2) 'サーマンの七部分の第二' : pra praev., ChU II. 8. 1: yat pra乞iti sa prastāvaḥ. cf. ädi- 1).

3）同上：prastuti- “讃美” (<pra-stu- “讚美す”), ChU II. 9. 3 : atha yat prathamođite sa prastāvas; tađ asya (ādityasya) manuṣyā anvāyattās; tasmāt te prastutikāmāḥ praśamsākāmāḥ; prastāvabhājino hy etasya sāmnah. cf. àdi- 2).

58. prāna- ‘氣息, 出息’, 1)：pra-aṇ- ‘出息す’, ChU I. 3. 3: yad vai prāṇiti sa prāṇạ. cf. àpāna-.

2): praṇayana-, pra-ṇī- ‘誘導す, 聖火を移し運ぶ’ PU IV. 3： yad gārhapatyāt praṇīyate, praṇayanād āhavanīyaḥ prāṇah.

cf. KeU I. 8: yat prāṇena na prāṇiti, yena prāṇaḥ praṇiyate...... (cf. Oerte1 JUB p. 244 ad Iv. 18. 9).

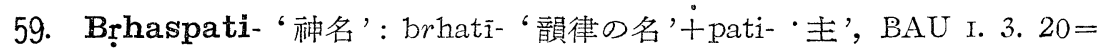
M I. 3. 22 : eșa $\mathfrak{u}$ eva bṛhaspatir, vāg vai bṛhatī, tasyā eșa patis, tasmād 11. bṛhaspatị̣ ; ChU I. 2. 11: etam (sc. prāṇam) u. eva bṛhaspatirn manyante, vāg ghi bṛhatī, tasyā eșa patis, tena.

60. Brahmaṇaspati- “神名': brahman- “呪詞'+pati- “主' BAU I. 3. 21=M I. 3.23 : eṣa û eva brahmaṇaspatir, vāg vai brahma, tasyā eṣa patis, tasinād u ( $M$ th ha) brahmaṇaspatih.

61. brahman- '呪詞' : bhṛ- '擔示' BAU I. 6. 1=M I. 6. 1: etad $(=$ vāc-) eșām (sc. nāmnām) brahma, etad dhi sarvāṇi nāmāni bibharti. simil. $2-3=$ M $2-3$.

62. bhaṇ- '話す' : bhāṇ onomatop. (息する音), BAU I. 2. 4=M I. 2. 4 : 
sa (sc. mrityuḥ) bhāṇ akarot; saiva vāg abhavat.

cf. M. Müller SBE xv, p. 76, n. 3, Senart p. xI. 原著者が bhaṇ, bhaṇati なる語を念頭に置いたのは明かである（cf. Deussen Sechzig Upanishad's p. 384)。但しこの語の言語學的語源に關しては, Walde-Pokorny：Verg1. Wb. II, p. 182 sub bhe1- 參照。從つて上記の語源は，例えば gharma- ‘プラヴァルギ ヤ祭に於ける牛乳㐗沸器=mahāvīra-' の語源を onomatop. ghrị (ŚB xIV. 1. 1. 10, v. Schroeder: Die Tübinger Kaṭa-Hss., 1898, p. 114) 叉は ghrāṇ (TA v. 1. 5) により說明するのと同巧異曲である。

63. bhargas- '光輝'，1): bhā- '光線'+gati- '進行'；2): bharjayati 3 . sg. praes. bhrj- (caus.) '乾し涸らす'; 3): bha-ra-ga-, i. e. bha (bhāsayati, 3. sg. praes. bhās- (caus.) '輝かす') + ra (rañjayati, 3. sg. praes. rañj(caus.) ‘喜ばす’) +ga (gacchanti, 3. p1. praes. gam-“赴く', à-gam- ‘來る’)。 MU vI. 7: p. 94. 1-p. 95. 3:1) atha bhargā iti yo ha vā amușminn āditye nihitas tārako (1. v. tārake) 'kșiṇi vaiṣa (1. v. caiṣa) bhargākhyo, bhābhir gatir asya hīti bhargo; 2) bharjayatīti vaișa bhargā iti rudro krahmavāđino; 3) 'tha bha iti bhāsayatīmāl 1okān, ra iti rañjayatīmāni bhūtāni, ga iti gacchanti 'asminn āgacchanty asmād imāḥ prajās, tasmād bharagatvād bhargah.

64. bhāmani- “光明の先導者': bhā- “輝く', ChU IV. 15. 4： eșa (i. e. akṣaṇi puruṣah) u eva bhāmañ̄r ; eșa hi sarveṣu lokeṣı bhāti; sarveṣu lokeșu bhāti, ya evaì veda. cf. vāmanī-.

65. bhūta- '實在, being': udbhūta- part. praet. ud-bhū- '發現す', MU v。 2: p. 76. 1: udbhūtatvād bhūtaìn, bhūteșu carati praviștạ̣ (sc. ātmā).

66 ma-kāra- 'マ音' : miti-<mi- (minoti) '建設す', 又は apiti-=*miti<mi- (mināti) '渻滅せしむ’, MāU 11: suṣuptasthānạ̣ prājño makāras tṛtīyā mātrā miter apīter vā, minoti ha vā idam sarva'm apītiś ca bhavati ya evain veda.

67. mauna- '沈默': man- '思考す', ChU viII. 5. 2 : atha yan maunam ity ācakșate, brahmacaryam eva tat; brahmacaryeṇa hy evātmānam anuvidya manute.

68. yajus- '祭詞' : yuj- '結合す', BAU v. 13. $2=\mathrm{M}$ v. 14. 2: prāṇo vai yajuḥ, prāṇe hīmāni sarvāṇi bhātāni yujyante ; yujyante hāsmai sarvāṇi bhūtāni śraiṣthyāya......ya evaị veda; KBU II. $6(\mathrm{~B})=$ II. 4 (A) : tad (sc. ưtham) yajur ity upāsīta, sarvāṇi hāsmai bhūtāni śraiṣthyāya yujjyante. 
69. ya jña- '祭祀', 1): yan nom. sg. masc., part. praes. i- '行く', ChU Iv. 16. 1: eșa ha vai yajño yo 'yam pavata; eșa ha yann idami sarvam punāti; yad eșa yann iđami sarvam punāti, tasmād eṣa eva yajñah.

2): yo jñāāā '知る者', ChU viII. 5. 1: atha yad yajña ity ācakșate, brahmacaryam eva tad; brahmacaryeṇa hy eva yo jñātā tam vindate.

70. yoga- “精神統一, 瑜伽”' yutj- '結合す', MU VI. 25： p. 145. 1-2: evami prāṇam athominkāram yasmāt sarvam anekađhā / yunakti yuñjate vāpi yoga iti smṛtạ̣ //

71. Rudra- p1. “神群の名’: rud- ‘叫ぶ’, caus. ‘叫ばしむ’, BAU III. 9. 4 =M III. 9. 5 : te (í. e. daśeme puruse prāṇā ātmaikadaśaḥ) yadāsmāc charīrān martyāe utkrāmanty, atha rođayanti; tad yad rodayanti, tasmād rudrā iti ; ChU III. 16. 3 : prāṇā vāva rudrā; ete hīdaì sarvami rodayanti. Rudra- の語源は Nir. x. 5 (: Skö1d p. 311-312, cf. TS I. 5. 1. 1, ŚB xI. 6. 3. 7, JB II. 77 : Oerte1 JAOS xv, p. 240, JUB Iv. 2. 6) 以來有名である が，その引用 (yad arıdat tad rudrasya rudratvam iti Kāthakam) の中に見 える artdat を, 現存 KS xxv. 1：p. 103.2 の文岣に合致せしめんが爲に， samarujat (Oerte1: Synsax of cases $\S 9$ Ex. 9, Rem.: p. 12) 或は arujat (Skö1d p. 13-14) に變更する必要はない。

72. lokya- '(父にその死後よき) 世界を與万る': 1oka- “世界', BAU I. 5. $17=$ M I. 5. 26: tasmāt putram anuśistami lokyam āhuh. cf. Hume p. 90. ก. 1 .

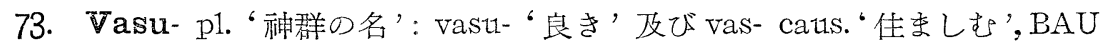
(M) III. 9. 4 : eteșu (sc. vasựu) hīdain sarvam vasu hitam; ete hīdain sarvamin vāsayante; tad yađ idam sarvamin văsayante, tasmād vasava iti, cf. K III. 9. 3: eteșu hīlami sarvarin (vasu ed. AnSS LXIV) hitam iti tasmād vasava iti; ChU III. 16. 1 : prāṇā vāva vasava; ete hīdamin sarvaị vāsayanti.

BAU (M) に於ける vasu 住不用の如く見えるが (cf. Senart. p. 57，n. 1)， JB II. 77 (: Oertel JAOS xv，p. 240）も同一の文句を有している。文 ete hīdam sarvain vāsayante はŚS XI. 6.3.6にも見えている。倚 Oerte1 JUB pp. 242-243 (ad Iv. 2.3) 參照。

74. vāman̄i- '良き多の導く者, porte-bonheur (Przyluski BSOS v.

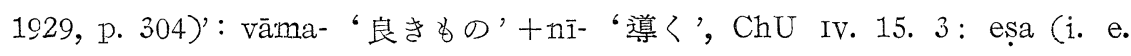
akșaṇi purușaḥ) u eva vāmanīr ; eșa hi sarvāṇi vāmāni nayati ; sarvāṇi vāināni nayati, ya evami veđa. cf. bhāmañ̄- 
75. Vāyu- “風神の名': āvayat 3. sg. imperf. av-, caus. “啖ふ’' (cf. Nigh. II. 8). 又は annāyu- “食を欲する’, AU I. 3. 10: tad (sc. annam) apāne-

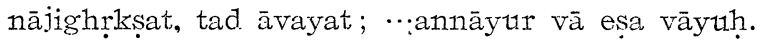

76. Vijarā- ‘神話的河の名' =vi-jarā- '不老' : na (否定辭) + jarayisyati 3. sg. fut. caus. j⿳亠̣⿵冂- '老ゆ': KBU I. 3 : mama yaśasā vijarām vā ayam nađììn prāpan, na vā ayaị jarayișyati.

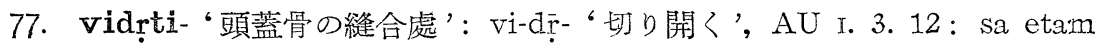
eva sīmantañ vidāryaitasya đvārā prāpadyata; saiṣā vidụtir raama dvās, tad etan nānđanam.

78. vidyut- “電光”! vidāna- “解放” 及び vidyati 3. sg. praes. vi-dā-“解 放す’, BAU v. 7. 1=M v. 7. 1: vidyud brahmety āhur, vidānād vidyuc, vidyaty enam (sarvasmāt M) pāpmano, ya evam veda: vidyud brahmeti.

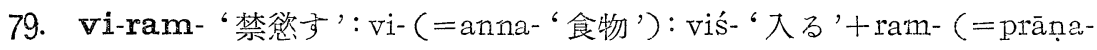
“生氣”) ‘喜ぶ’, BAU v. 12. 1=M v. 13. 3 ; tasmā u haitad uvāca: vi_ity, annam vai vy, anne hy imāni bhūtāni viṣtạni ; ramn iti, prāṇo vai ram, prāṇe bìmāni sarvāṇi bhūtāni ramante (M ratāni); sarvaaṇi ha vā asmin bhūtāni viśanti, sarvāṇi bhūtāni ramante, ya evam veda.

80. vaidyuta- “電光の如き': vi-dyut- caus. ‘輝か子’, MU VII 11：p. 215. 2-p. 216. 2: atha kaśmād rcyate vaidyuto; yasmäd uccāritamātra eva (sc. omkāraḥ) sarvam śarịram vidyotayati, tasmāo om ity anenaitad uxpāsītāparimitain tejah.

81. samyadvāma- “良きものを䊼合する': abhisamyanti 3. p1. praes. abhi-sam-i- “向いて集り來る'十vāma- “良きもの', ChU Iv. 15. 2 : etam (i. e. akșaṇi purușam) samyadvāma ity ācakșata; etam hi sarvāṇi vāmāny abhisamyanti; sarvāṇy enain vāmāny abhisaṅyanti, ya evani veda.

82. sattrāyaṇa- '長期のソーマ祭’ : sat̀- “實在する, 真實の' (part. praes. as- 'sein') +trāṇa- '救濟', ChU vili. 5.2 : atha yat sattrāyaṇam ity äcakșate, brahmacaryam eva tad; brahmacaryeṇa hy eva sata àtmānạ̣ trāṇam vindate.

83. satya- '真實, 真理', 1): sat- '實有, das Seiende'+tyam=tyat pron. dem. neut. (cf. Wackernage1 A1tind. Gr. III, p. $547: \S 256$ b $\delta$, Fürst KZ XLVII, p. $1 \dot{8}$, p. 56) 'das Jenseitige, 1e transcendant', BAU II. 3. $1=\mathrm{M}$ II. 3. 1: dve vāva brahmaṇo rūpe $\cdots . .$. sac ca tyam ca (i. e. sat-tyam=satyam, cf. e. g: v. $4.1=\mathrm{M}$ v. 5. 1 : satyam brahma) ; KBU I. 6 : kim tad yat saty- 
am iti, yad anyad devebhyaś ca präṇebhyaś ca tat sad, atha yad devāś ca prānāś ca tat tyam, tad etayā (Berlin-mıs. ekayā, v. Keith ŚA tr., p. 20, n. 5) vācābhivyāhriyate satyam iti; TU II. 6: tad (i. e. idarin sarvam) anupraviśya sac ca tyac cābhavat.....; satyam abhavad yađ idain kimca, tat satyam ity ācakșate.

この語源は 3）と同しく sattyam なる發音を豫定している, cf. Wackernage1 Altind. Gr. I, p. $113: \S 98$ a, Anm.

2)：sa-ti-yam（文は - $\mathrm{am}$ ), 音節 sa 及び ( $\mathrm{y}$ ) am は“實在 (satyam)’を意味 L, ti-i 注無意味の附加音 (anubandha) 一は ‘不䢐實 (anrta-=mrtyu- ‘死') を示す，何となれば $\mathrm{t}$ 香はこれ等兩語に含まれている， BAU v. 5. 1=M v. 6. 2 : tad etat tryakșaram satyam iti; sa ity ekam akṣaram, ti_ity ekam akṣaram, yam (M am) ity ekam akșaram; prathamottame akșare satyam, madhyato 'nrtam.

cf. Śañkara ad loc., Dvivedaganga ad ŚB xIv. 8. 6. 2 (ed. Weber, p. 1159 fin.-p. 1160. 1), M. Mü1ler SBE xv, p. 191, nn. 3 et 4, Deussen p. $491 \mathrm{cum}$ n. 1, Senart p. 94, n. 2.

3): sat =amrtam '不死'+ti= martyam '應死' +yam : yam-, yacchati '統持 す’, ChU viIr. 3. 5: tāni hi vā etāni trịṇy akṣarāṇi sat-ti-yam iti; tad yat sat tad amrtam, atha yat ti tan martyam, atha yad yam tenobhe yacchati; yad anenobhe yacchati tasmād yam.

84. samāna- '五氣の一' < sam-an- '呼吸与', 1): samam “等しく'+ nayati 3. sg praes. nī- '導く' (本等にす), PU III. 5: madhye tu samānaḥ; eṣa hy etad dhutam annamin samamin nayati. Iv. 4: yad ucchvāsaniśvāsāv etāv āhutī samạm nayatīti samānaḥ.

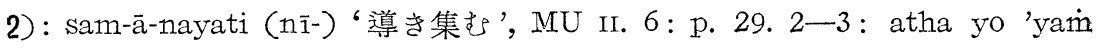
sthaviștho dhātur annasyāpāne prāpayaty, aṇiștho vānge-'nge samānayaty, eṣa vāva sa samānasamiñah. cf. rec. austr.: atha yo 'yam sthavișţham annađhātum apāne sthāpayaty, aṇiștham cānge-'nge samam nayaty, eṣa vāva sa samānaḥ. v. supra 1).

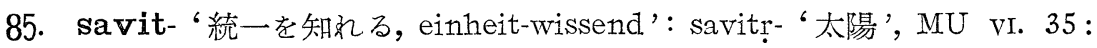
p. 186. 1-2: nabhaso 'ntargatasya tejaso 'minśāātram etad, yad ādityasya madhye (sic) udutvā (ưitvā) mayūkhe bhavata, etat savit.

savit-の真意に關しては, ib. p. 187. 4:yo haivamit sa savit, sa dvaitavit に照して疑いはないが，語形から見て savitr- との同一を念頭に置いたことの可 
能性を考えてここに加えた。 cf. comm.: savitrrūpah, Cowe11 p. $282 \mathrm{cum}$ n. †, M. Mü11er SBE xv, p. 336 cum n. 1.

86. savitr- '太陽', 1)： savana- < sū-, suvati “刺戟す', MU vI. 7 : p. 95. 3 : savanāt savitā.

2): sūyante 3. p1. pass. < sū-, sūte '生む', MU vi. 16: p 124. 1-3: eṣa tatsthạ savitākhyo (sic), yasmād eveme candraṛısa(1. v. candrarkṣa)grahasaninvatsarādayạ sūyante.

87. sāman- '歌咏, 旋律”， 1) sā pron. dem. fem. (女性物の總稱として), + amah pron. indef. masc. (男性物の總稱として), BAU I. 3. 22=M I. 3. 24 : eșa (sc. prāṇaḥ) u eva sāma; vāg vai sāma; eșa sā ca`amaś ceti. tat sāmnạ̣ sāmatvam; ChU I. 6. 1: iyam (i. e. pṛthivī) evarg, agnị̣ sāma; tad etad etasyām ṛcy ađhyūạham sāma; tasmād ṛcy adhyūụhàm sāma gĩyata, iyam eva sā, ağnir amas, tat sāma, simil. 2-6, I. 7. 1-4, cf. Weber ISt v, p. 216, Oerte1 JUB p. 235 (ad. I. 53. 5), p. 258 (Index sub sāman), Caland AO vI, p. 145, Wackernagel Altind. Gr. III, pp. 532-533: $\$ 251$ h cum Anm. (1it.).

2): sama- ‘同じき’, BAU I. 3. $22=\mathrm{M}$ I. 3. 24 : yad $\mathrm{v}$ eva samah plusiṇā, samo maśakena, samo nāgena, sama ebhis tribhir 1okaih, samo 'nena sarveṇa, tasmäd v eva sāma; BAU I. 6. 1=M I. 6. 1: etad (=vāc-) eșām (sc. nāmnām) sāma, etad dhi sarvair nāmabhị̣ samam, simi1. 2-3=M 2-3; ChU II. 9. I : atha Khalv amum ādityam saptavidham sāma_upāsīta ; sarvadā samas, tena sāma; māin prati māmi pratīti sarveṇa samas, tena sāma.

3)： samyac- ‘統合せられたる’，BAU v. 13．3=M v. 14. 3： prāṇo vai sāma; prāṇe hīmāṇi sarvāṇi bhūtāni samyañci; samyañci hāsmai (M hāsmint) sarvāṇi bhūtāni śraiṣthyāya ka1pante.

4): sādht1- '正しき', asāman- 'サーマンならざるもの': asādht1- '正しか らざる', ChU II. 1. 1: samastasya khalu sāmna upāsanami sāđhu, yat khalu sādhu tat sāmety ācakṣate, yad asādhu tad asāmeti, 2 : tad utāpy āhụ : sāmmā (sāman-'友椬') ¿enam upāgād iti, sādhunā_enam upāgāà ity eva tad āhur, asāmnā_enam upāgād. ity, asāđhuñā_enam upāgād ity eva tad. àhụ. 3: athotāpy āhụ̣̂ : sāma no bateti ('wir haben vollauf, es geht uns gut' PW, sāman- (繁榮'), yat sādhtı bhavati, sādhu batety eva tad āhur; asāma no bateti, yad asādhu bhavaty, asādhu batety eva tad āhuh. 4: sa ya etad evain vidvānt sādhu. sāmety upāsta, abhyāśs ha yad enamin sādhavo 
đharmā à ca gaccheyur, upa ca nameyuh.

5): samnamante 3. p1. praes. sam-nam- “敬禮す', KBU II. 6 (B) =II. 4 (A): tat (sc. uktham) sāmety upāsīta, sarvāṇi häsmai bhūtāni śraiṣthyāya samnamante.

88. sukrta-“善く造られたる’: svayam “自ら’+kr “造る’, TU II. 7 : tad ātmanam svayam ałuruta, tasmāt tat sukrtam ๘cyate.

89. suvarṇa- '黃金”' svara- “音', BAU I. 3. $26=$ M I. 3. 28 : tasya (sc. sāmnaḥ) vai svara eva suvarṇami ; bhavati hāsya stuvarṇam, ya evam etat sāmnaḥ suvarṇain veda.

90. sūrya- '太陽': sūyamāna- part. praes, med. su1-, stunoti '(ソーマ液

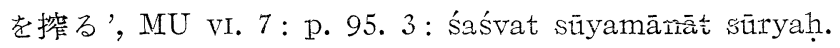

91. Srști- ‘創造’' srjj- med. ·創造す’, BAU I. 4. 5=M I.' 4. 10： so (sc. àtmā) 'ved: aham vāva ș̣sțir as.ry, ahain hy idani sarvam aṣ̣kṣịti ; tatạ sṛstitir abhavat.

92. Skanda- “神名, Sanatk'umāra', ChU vir. 26. 2: tasmai mṛditakașāyāya ta asạ̣ pāram darśayati bhagavàn sanatkumāras; tam skanda ity ācakșate.

原著者の意圖は明瞭でないが，恐らく“暗黑の彼岸を示す’ と云ふ背後に, tamo 'tiskandayati の如き文訽を豫想したものと考えられる, cf. Hume p. 262， n. 3, 宇井伯壽 ウパニシャッド全書 III, p. 198, n. 2.

93. svapiti 3. sg. praes. svap-“眠る': svam, ‘自己'+apita-“到達せる', ChU vi. 8. 1 : yatraitat puruıạ svapiti, satā somya tadā sampanno bhavati; tasmād enaì svapitîty ācakșate; svaìn hy apīto bhavati.

94. svara- '音': svar- '太陽', ChU I. 3.2: svara iti_imam (sc. prāṇam) ācakṣate, pratyāsvara ity amum (sc. ādityam).

svara-は‘音’を意味すると同時に, svar- ‘太陽”を想起せしめる。更にこの 意義を明瞭にする篇に，太陽に關して pratyāsvra-なる語を用い, “区響” “反射” の兩義を含ましめたるのと解される。昇る太陽と音響との關係は他の 简所に於ても認められる。郎ち太陽恃昇りつ〉人界を呼び學し（ChU I. 3. 1: udyan vā eșa prajābhya udgāyati; I. 5. 1 et 3: om iti hy eșa svarann eti), 萬物は昇る太陽を仰いで歡聲を舉げる（ib. I. 11. 7 : sarvāṇi ha vā imāni bhūtāny ādityam uccaị santam gāyanti ; III. 19. 3)。

95. hinkāra- ‘サーマンの七部分の第一', 1): htım interj., ChU II. 8. 1: yat kiminca vāco hum iti sa hinkzārah. cf. ādi-1)。 
2): hin-kr- ‘hum なる音を發す’ ChU II. 9. 2: tasya (sc. ādityasya) yat purođayāt sa hinikāras; tad asya paśavo 'nvāyattās; tasmāt te hinkłurvanti ; hinkārabhājino hy etasya sāmnaḥ. cf. ādi- 2).

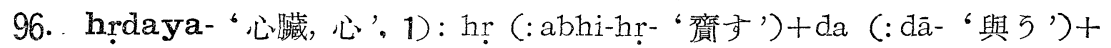
yam (: i- “行〈'), BAU v. 3. 1=M v. 4.1: tad etat tryakșaram hṛayam iti ; hṛ ity ekam akṣaram, abhiharanty asmai svāś cānye ca, ya evaìn veda; da ity ekam akṣaram, dadaty asmai svāś cānye ca, ya evain veda; yam ity ekam aksaram, eti svargam 1okam, ya evarin veda.

2): hṛdi loc. sg. hrd- '心臟, 心'+ayam pron, dem. nom. sg. masc., ChU viIr. 3. 3 : sa vā eșa ạtmā hṛ̣ii; tasyaitad eva niruktain, hrọdy ayam iti tasmād dhṛ̂ayam.

\section{アメリカのインド學者}

I) History: Crane, Robert I., Aspects of Indian history. Yale and Am. Council of Learned Societies; Lindblad, Goethe M., Background and consequences of the Cripps mission to India. Southern California; Rentz, George S., The Wahhabite movement and its significance (parts of Ph. D. 1947). California, Berkeley; Thorner, Danie1, British nationalism in India, 1850-80. Columbia; II) Geography and Economics: Abraham, Wa1ter, A theory of India's economic development. Yale; Brush, John, Ratio map showing distribution of religions groups by districts. Wisconsin; Brush, John and Nath, V., New map of climate of India. Wisconsin; Eggerding, Roland, Distribution of manufacturing in India; maps and text. Wisconsin; McCune, Shannon (F), Sequences of plantation agriculture in Ceylon. Colgate; Orchard, John E. (F), and Orchard, Dorothy J. (F), India's industrialization. Columbia; III) Anthropology, Sociology, Religion, Education: David, Braduku, Brahmanical and vernacular interaction in the modern Telugu country. ( $\mathrm{Ph}$. D.). Yale; Davis, Kingsley (F), Population and social organization in India. Office of Population Research, Princeton; Elliot, Vida Cos, Education of the Hindu woman (Ph. D. 1947). Hartford theol. Sem.; Majumdar, Nabendu Datta, The Santa1: a study in acculturation. Northwestern; Mandelbaum, David G. (F), Life of the Kota (southern India) (monograph). California, Berkeley; Sampson, N. F., Benga1 folklore. Univ. of Arizona; Shrimali, Kalula1, The Gandhian plan of education for rura1 India (Ph. D. 1947). Teachers Col., Columbia; Worman, Eugene C., Jr., The problem of neolithic culture in India (continuation of Ph. D. 1946). Havard and National Reserch Counci1; N) Language and Literature: Bender, Ernest, Indian linguistics (field study). Pennsylvania and Am. Council of Learned Societies; Edgerton, Franklin, Grammar and dictionary of Buclhist Hybrid Sanskrit. Yale; Hein, Norvin J., Indian drama, with special reference to the modern scene (Ph. D.). Yale; Trottunga1, Abraham John, A critical study of the sources of early Christianity in India. Hartford Theol. Sem. (以上 Far Eastern Quarterly VII，1947 Кょる，各學者の下には最近の研究問題を 記す. F. は Faculty member の略.) 